\title{
Studies of Mass-Movement Processes ON SUbMARINE SLOPES
}

By Lincoln F. Pratson, Homa J. Lee, Gary Parker, Marcelo H. Garcia, Bernard J. Coakley, David Mohrig, Jacques Locat, Ulisses Mello, Jeffrey D. Parsons, Sun-Uk Choi and Kenneth Isreal

n continental

slopes, the dominant

processes that affect

the stratigraphic

record are gravity

driven . . .
$\mathrm{T}$ HE OBJECTIVE OF THE STRATAFORM program of the Office of Naval Research (ONR) is to understand how the stratigraphy of continental shelves and continental slopes is created and preserved by the processes operative in these environments. On continental slopes, the dominant processes that affect the stratigraphic record are gravity driven and commonly involve mass movements of sediments by creep, slumps, slides, debris flows, and/or turbidity currents. Collectively these processes are a major force in sculpting continental slope morphology, creating such features as failure scars and submarine canyons. The processes are episodic and tend to be localized. Their occurrence dictates where sediment is preserved on continental slopes and where it is not. The unconformable surfaces they erode are complex, discontinuous and asynchronous, complicating the interpretation of continental slope stratigraphy, particularly as it relates to past environmental changes such as fluctuations in sea level. A goal of STRATAFORM is to develop models that can aid in predicting where and how mass movements could occur, and what role these events play in continental-slope evolution. To meet this goal, project members are pursuing several key objectives in studying the New Jersey and northern California continental slopes. These objectives are to:

- Quantify the causes of slope failure;

- Document the mechanics and progression of mass movements spawned by slope failure;

Lincoln F. Pratson, Institute of Arctic and Alpine Research, University of Colorado, Boulder. CO 80309, USA; Homa J. Lee. Kenneth Isreal, U.S. Geological Survey, Menlo Park, CA 94025, USA: Gary Parker. David Mohrig, Department of Geology \& Geophysics. University of Minnesota. Minneapolis, MN 55455, USA: Marcelo H. Garcia, Jeffrey D. Parsons, Sun-Uk Choi. Department of Civil Engineering. University of Illinois, Urbana-Champagne, IL 61801, USA: Bernard J. Coakley, Lamont-Doherty Earth Observatory of Columbia University, Palisades. NY 10964, USA; Jacques Locat, Department of Civil Engineering, Lavelle University. Quebec. Canada: Ulisses Mello, IBM T.J. Watson Research Labs, Yorktown Heights. NY 10598, USA.
- Determine how mass movements link to slope morphology and stratigraphy.

\section{Approach}

Not enough is yet known about submarine slope failure and mass movements to reliably anticipate when, where, or how they may occur. Additionally, observation of these processes is hindered by the remoteness of the marine environment, and by the fact that the effect of mass movements on continental-margin evolution is cumulative, spanning geological rather than human time scales. To circumvent these difficulties, a threepronged approach of field, laboratory, and modeling studies is being used to achieve the above objectives. The field studies are examining lithological, mechanical, morphological, and stratigraphic attributes of failed and unfailed seafloor sediments to determine the causes of submarine slope failures and to predict their future occurrence. The laboratory studies are using flumes to quantify the dynamic evolution of different types of mass movements spawned by slope failure. And the modeling studies are constructing computer algorithms that simulate how, over time, mass movements contribute to the formation of continentalslope morphology and stratigraphy. Preliminary accomplishments made by each of these studies are described in the following sections.

\section{Field Studies}

The field investigations of slope failure have focused on the continental slope within the northern California STRATAFORM study area, where many factors thought to induce slope failure are prevalent. Sediments from the Eel River are reaching the slope and accumulating at relatively rapid rates (1-4 mm $y^{-1}$ ) (Alexander, 1996), which can lead to excess pore pressures and seafloor destabilization (Terzaghi, 1956). The slope contains zones of buried gas hydrates (Syvitski et al., 1996, this issue) and the seafloor in the northern part of the study area is pockmarked with small craters formed by seeping gas (Goff et al., 1996, this issue), which can also destabilize the seafloor. And. due to the tectonic collision occurring between the North American 
and Juan de Fuca plates in this region, the area is periodically subject to earthquakes.

A combination of these processes (earthquake and gas) could have caused the large Humboldt slide in the southern part of the study area (Lee $\mathrm{et}$ al., 1981; Field and Barber, 1993). And new swath-mapping imagery and high-resolution seismic profiles suggest this slide actually formed by more than one type of mass movement process (for a detailed discussion of this data and of the Humboldt slide, see Goff et al., 1996, this issue, and Syvitski et al., 1996, this issue). Other parts of the slope may be prone to future failures.

A key goal of the field studies is to identify which types of measurements in this area (when mapped regionally) can be used to constrain where slope failures might occur, how large and deepseated these failures would be, and what forms of mass movements they would produce. For example, sediment properties that can be rapidly measured and mapped in the field, such as wet-bulk density and Atterberg limits, are being tested as proxies for sediment shear strength. If successful, these proxies will then be compared with estimates of gravity-induced downslope shear stresses made from maps of seafloor slope to predict the minimum earthquake magnitude that could trigger slope failure.

To date, 120 box-core subsamples and 5 piston cores have been recovered from the study area. All the cores have been logged for wet-bulk density, sound velocity, and magnetic susceptibility at a resolution of $1 \mathrm{~cm}$. The wet-bulk-density measurements, which have been corrected for depth in the cores, reflect the lithology and stress history of the sediments, and they will eventually be used to estimate variations in sediment shear strength. Figure 1 is a map of these density measurements. Comparison of this map with sediment accumulation rates determined from the cores (Syvitski et al., 1996, this issue) indicates that sediments with low $\left(<1.5-1.7 \mathrm{~g} \mathrm{~cm}^{-3}\right)$ wet bulk densities occur in the active depocenters on the slope (green and blue areas in Fig. 1). These sediments are fine-grained and are accumulating rapidly $(1-4 \mathrm{~mm}$ $\mathrm{y}^{-1}$ ) (Alexander, 1996). Sediments with higher wetbulk densities ( 1.7 to $>2.0 \mathrm{~g} \mathrm{~cm}^{-3}$ ) occur along other portions of the slope (red and pink areas in Fig. 1). These sediments are coarser grained, but their higher densities may also reflect erosion of overburden.

\section{Laboratory Studies}

Whereas the field studies are focusing on the causes of submarine slope failure, the laboratory studies are focusing on the dynamics of mass movements spawned by slope failures. Unique flumes are being used to simulate and collect direct measurements of these processes. The measurements are in turn being used to develop and calibrate numerical models of the processes. So far, the flume experiments have centered on the dynamics of subaqueous debris flows and the propagation of turbidity currents.

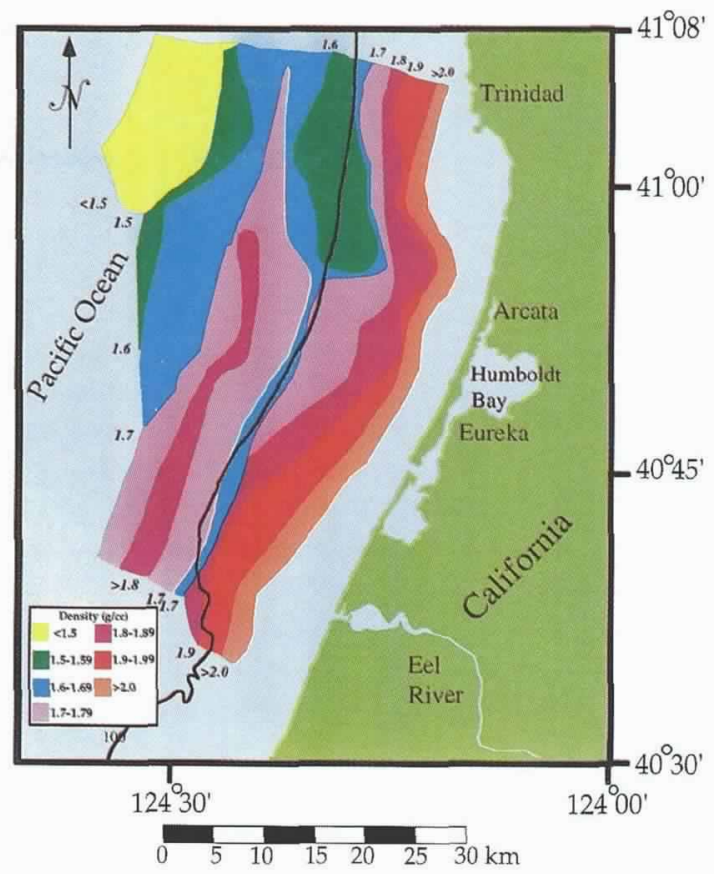

Fig. 1: Contoured seafloor wet-bulk densities as determined at $10 \mathrm{~cm}$ depth in 125 cores taken within the northern California STRATAFORM study area. On the portion of the continental slope investigated, areas of low $\left(<1.5-1.7 \mathrm{~g} \mathrm{~cm}^{-3}\right)$ wetbulk density (green and blue areas) occur where fine-grained sediments are actively accumulating. Areas of higher ( 1.7 to $>2.0 \mathrm{~g} \mathrm{~cm}^{-3}$ ) wet-bulk density (red and pink areas) occur where sediments are coarser grained, but also where overburden may have been eroded. Additional factors influence the bulk densities of sediments on the shelf.

The experimental program investigating the dynamics of debris flows is based at St. Anthony Falls Laboratory (SAFL) of the University of Minnesota. The lab has recently completed construction of a new type of flume containing a $0.2-\mathrm{m}-$ wide channel with transparent walls that is suspended in a tank $10 \mathrm{~m}$ long, $3 \mathrm{~m}$ high, and 0.6 $\mathrm{m}$ wide. Flows initiated within the flume can be observed through a side wall and from above the flume along the entire length of the channel.

A major finding from one of the first sets of experiments run in the flume is an explanation for why the heads of subaqueous debris flows can move substantially faster and farther than those of subaerial debris flows (Mohrig et al., 1995). The SAFL experiments indicate that under appropriate conditions the heads of the submarine debris flows hydroplane. In the flume, the heads of debris flows are observed to override a wedge of the water in front of them and detach from the flume channel floor (Fig. 2), significantly reducing the bed friction that would otherwise retard their movement.
... laboratory stud-

ies are focusing on

the dynamics of

mass movements

spawned by slope

failures. 
... to link individual

models of different

mass-movement pro-

cesses .... in order

to correctly simulate

. . . morphology and

stratigraphy ...
This hydroplaning, which is directly analogous to the way tires hydroplane on wet roads (Horne and Joyner, 1965), offers one of the first physical explanations for the long run-out distances often observed for submarine debris flows deposited on seafloor slopes of $<1^{\circ}$ (Embley and Jacobi, 1986).

A second experimental program investigating the initiation, spatial development, and duration of turbidity currents, as well as the characteristics of the sedimentary deposits these flows generate is being led by the Department of Civil Engineering at the University of Illinois. In this program, turbidity currents are studied using a second flume that arrests the front of a turbidity current by generating a fresh water flow that moves in the opposite direction of the turbidity current with the same mean velocity as the current front. A conveyor belt is used to ensure that the speed of the bed equals that of the water flow so that the turbiditycurrent front remains stationary and can be studied in detail (Garcia and Parsons, 1996).

Measurements of dilute suspended-sediment flows (i.e., sediment concentrations $<26.5 \mathrm{~g} \mathrm{l}^{-1}$ or $0.0265 \mathrm{~g} \mathrm{~cm}^{-3}$ ) made using this flume have contributed to the development of both one-dimensional and two-dimensional numerical models of how turbidity currents propagate. Results from the one-dimensional model, which predicts the evolution of turbidity-current height, velocity, and concentration with increasing distance from its source (Choi and Garcia, 1995), are shown in Figure 3. Other flume measurements indicate that in dilute turbidity currents, most of the mixing at the current front is due to billows (known as KelvinHelmholtz billows) that roll up above the front as the current moves downslope. This frontal mixing

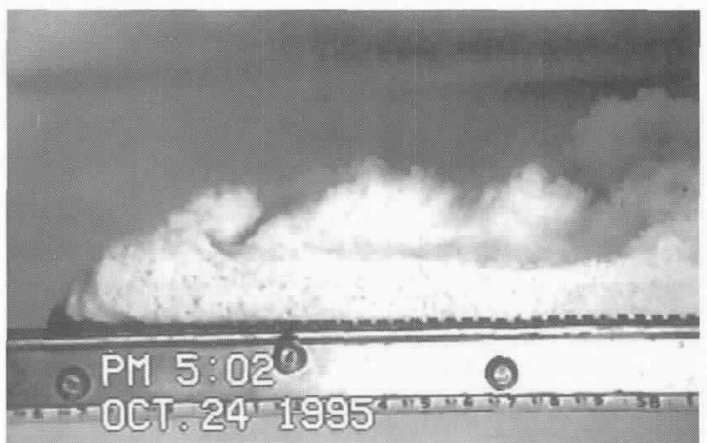

Fig. 2: Head of a subaqueous debris flow and overlying suspended-sediment cloud simulated within the flume at St. Anthony Falls Laboratory of the University of Minnesota. Note how the head of the debris flow is overriding the wedge of water in front of it and has detached from the grooved, dark-colored flume bed. This greatly reduces the bed friction that would otherwise retard the movement of the debris flow, allowing it to travel much farther downslope than it would under subaerial conditions. Image length is $49 \mathrm{~cm}$. is quite different from the hydroplaning mechanism (above) that appears to facilitate the movement of denser debris flows (i.e., sediment concentrations of $\sim 1,000 \mathrm{~g} \mathrm{l}^{-1}$ or $1 \mathrm{~g} \mathrm{~cm}^{-3}$ ), and may be an important reason for the differences between depositional structures in deposits formed by turbidity currents versus those formed by debris flows.

\section{Modeling Studies}

Correctly scaling the flume measurements of mass-movement processes to the real world is one of the major goals of the computer modeling studies. Another is to link individual models of different mass-movement processes with models of other slope processes in order to correctly simulate how the morphology and stratigraphy of continental slopes evolve over geological time.

A first step toward the latter goal has been the development of a seascape evolution model (Pratson and Coakley, 1996). This model simulates continental-slope morphology that results from the interaction between sedimentation, slope failure, and sediment flow erosion. The processes are emulated by discrete interactions between cells in a grid of continental-slope topography that evolves over the course of a model run. The model predicts that submarine canyons evolve on continental
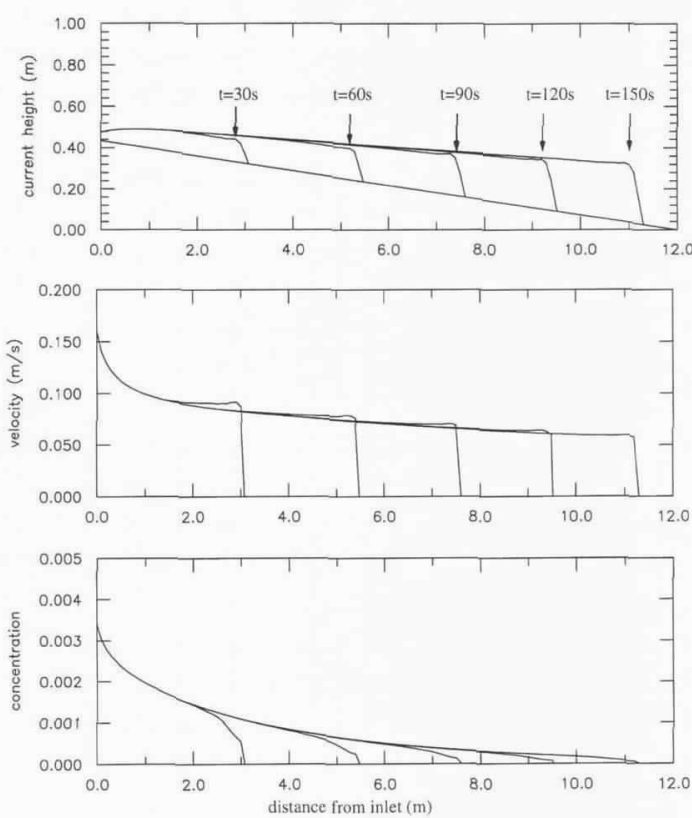

Fig. 3: Results from a one-dimensional model that predicts the evolution of a turbidity current as it propagates down a sloping channel. Top panel shows that the height of the turbidity current will increase with increasing time and distance from its point of initiation due to the entrainment of ambient water. This entrainment, along with the deposition of sediment from the flow, causes corresponding decreases in the velocity (middle panel) and concentration (bottom panel) of the turbidity current. 
slopes in three stages: 1) where sedimentation oversteepens the upper continental slope and causes it to fail, sediment flows (e.g., turbidity currents) are triggered, and these cut relatively narrow gullies that extend to the base of the slope (Fig. 4A); 2) some of these slope gullies become pathways for subsequent sediment flows, and, as a consequence of the enhanced downcutting on the mid to lower slope, their walls fail (Fig. 4B); and 3 ) these mid- to lower-slope failures then evolve into headward-eroding submarine canyons that advance upslope along the gullies by further retrogressive failure, where sediment flows enter the canyons and undercut their headwalls (Fig. 4, C and D). This sequence for canyon evolution successfully replicates cross-cutting relations between intercanyon and canyon morphologies on the tectonically passive New Jersey continental slope and on the tectonically active Izu-Bonin fore arc off Japan.

A second, related model has been developed to simulate the progressive buildup of stratigraphic sequences deposited by sediment flows. Like the seascape evolution model, this model is rule-based and operates in map view. Sediment flow movement and deposition are linked to seafloor morphology, which dictates convergence or divergence of a sediment flow as it moves down slope. Figure 5 shows examples of how sediment is routed and deposited across the seafloor in the model. In these examples, a sequence of sediment flows across a sediment prism built by previous sediment flows earlier in the model run. From their entrance into the model at base of the continental slope, the flows produce continuous conduits analogous to channels. These conduits, which have a constant, "graded" slope, extend across the sediment prism and direct sediments to its seaward front. Successive flows cause the conduits to periodically switch and reorganize, particularly at their distal ends. This result is analogous to the channel switching and abandonment that occurs on submarine fans (see Weimer and Link, 1991 and papers therein). However, in contrast to the concave profile of submarine fans, the model forms a sediment prism with a table-top-like profile (i.e., the sediment prism aggrades to a certain thickness, and then grows basinward by the buildup of deposits along its distal front). This behavior results because sediment transport and deposition are parameterized in the model only in terms of seafloor slope. Other factors that determine where and how much a sediment flow deposits, such as its velocity, discharge, etc., now need to be considered as well.

\section{Future Work}

Research is already underway to expand on and integrate the investigations summarized above and in other articles in this issue. A major emphasis of this new work will be on using the laboratory and modeling techniques described above to help ex- plain and correctly reproduce observations related to mass movement processes being compiled by the field investigations in the STRATAFORM study areas. When all the cores from the northern California study area are analyzed, the data will be coupled with the swath-mapping imagery, highresolution seismic-reflection profiles, and other information (e.g., earthquake distributions and magnitudes) in a Geographic Information System (GIS). The GIS will facilitate correlations between these data, which in turn will be used to constrain the present stability of the area, and its relationship to the seafloor morphology and subsurface stratigraphy. This combination of data also will be used to constrain the types of mass-movement processes operative in the area and their regions of influence.

Drawing on this information, the laboratory studies will attempt to simulate in flumes how mass-movement processes formed two key features on the northern California slope: the Humboldt slide and the gullies that incise the shelfbreak in the northern part of the study area (see Goff et al., 1996, this issue). Flume experiments will examine the possibility that the Humboldt slide initiated a turbidity current, and if so, what percentage of the original sediment was removed from the study area by this process. The formation of the slope gullies will be studied in a new experimental tank containing a model continental shelf and slope surface.

The modeling studies will use the results from the flume experiments in three ways. One is to
A.

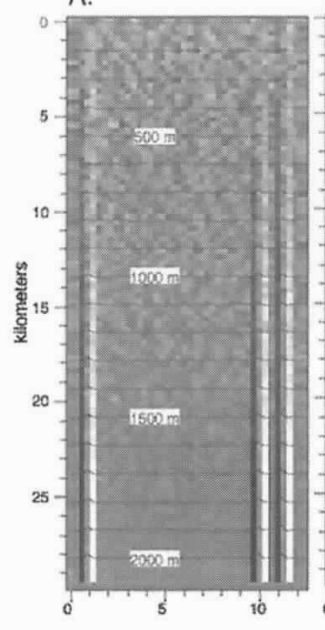

B.

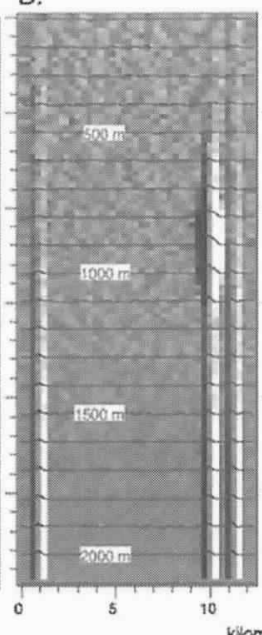

C.

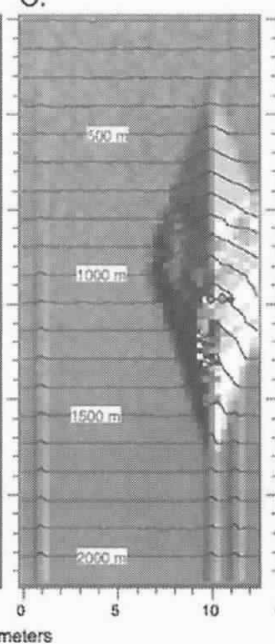

D.

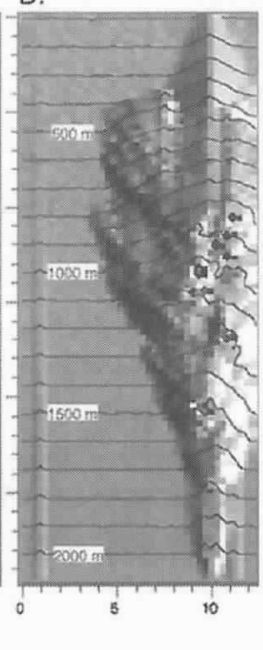

Fig. 4: The sequence of submarine-canyon evolution simulated by a first-version seascape-evolution model. (A) The sequence begins with turbidity currents, triggered by slope failures where the slope has been oversteepened by sedimentation, cutting narrow shallow gullies to the base of the slope (bottom of panels). (B) Repeated use of a gully by the turbidity currents oversteepens the gully wall and causes it to fail. (C) The initial failure triggers retrogressive failures that expand the gully into a canyon. (D) Additional turbidity currents enter the canyon and undercut the canyon walls, causing further retrogressive failures that expand the canyon and lead to the upslope migration of the canyon head. From Pratson and Coakley (1996). 
. . mass-movement

processes formed

two key features on

the northern California

slope: the Humboldt

slide and the

gullies . . .
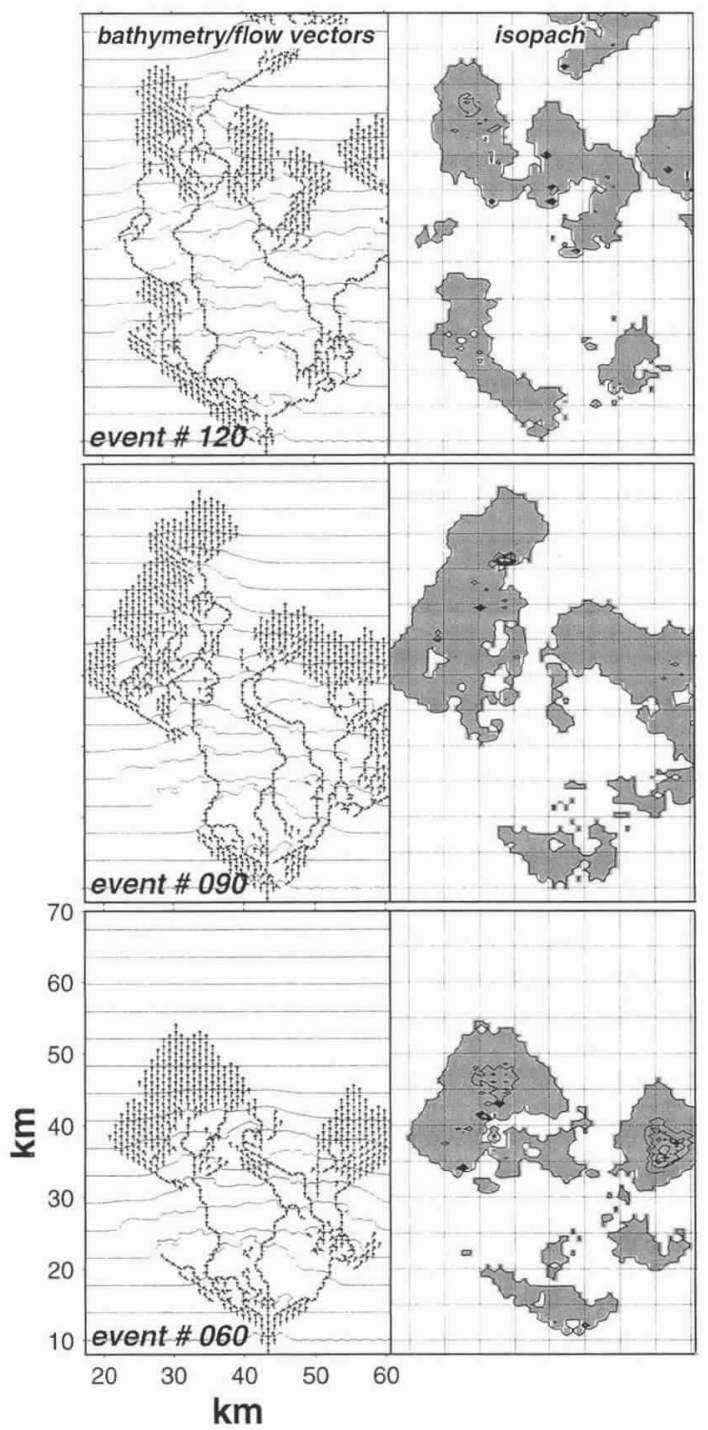

Fig. 5: Matrix of results from a map-view model that simulates the progressive buildup of stratigraphic sequences deposited by sediment flows. Bottom row shows the results associated with the 60 th sediment flow simulated by the model; middle row shows the results associated with the 90th sediment flow; and top row shows the results associated with the 120th sediment flow. Left column shows the preexisting bathymetry (contours) for the sediment flows, overlain by vectors that indicate the paths of the flows and how they diverged. Right column shows the areas over which sediments were deposited by each sediment flow.

continue to develop numerical models of debrisflow and turbidity-current dynamics. These models will be extended to two dimensions and will include a new model that simulates the initiation of turbidity currents from debris flows. The second use of the flume experiments will be the incorporation of the turbidity-current "spreading laws" into the seascape evolution model. These formula- tions will improve how the model simulates the interaction between turbidity currents and other slope processes while maintaining a reasonable computation time. The third use of the flume experiments will be to calibrate the seascape evolution model. Selected flume experiments will be simulated with the model to determine how well it reproduces the experiment results and what aspects of the model need to be modified.

\section{Acknowledgements}

Funding for the generation of the manuscript and the research it highlights was provided by the Office of Naval Research, with special thanks to J. Kravitz, ONR program manager of STRATAFORM. We thank D. Prior, R. Bennett, C. Nittrouer, and J. Kravitz for their review of the original version of this manuscript.

\section{References}

Alexander, C.R., 1996: Slope sedimentation on the Eel River continental margin. EOS Transactions of the AGU, 76, OS 10.

Choi, S.U. and M.H. Garcia, 1995: Modeling of one-dimensional turbidity currents with a dissipative-Galerkin finite element method. J. Hydraul. Res. IAHR, 33, $623-$ 648.

Embley, R.M. and R. Jacobi, 1986: Mass wasting in the western North Atlantic. In: The Geology of North America, Vol. M, The Western North Atlantic Region. P.R. Vogt and B.E. Tucholke, eds. Geol. Soc. Am., 479-490.

Field, M.E. and J.H. Barber, Jr., 1993: A submarine landslide associated with shallow seafloor gas and gas hydrates off northern California. In: Submarine Landslides: Selected Studies in the U.S. Exclusive Economic Zone. W.C. Schwab, H.J. Lee and D.C. Twichell, eds. U.S. Geol. Surv. Bull., 2002, 151-157.

Garcia, M.H. and J.D. Parsons, 1996: Mixing at the front of gravity currents. Dyn. Atm. Oc., 24, 197-205.

Goff, J.A., L.A. Mayer, J. Hughes-Clarke and L.F. Pratson, 1996: Swath mapping on the continental shelf and slope: the Eel River Basin, northern California. Oceanography, 9, 178-182.

Horne, W.B. and U.T. Joyner, 1965: SAE Technical Paper 970C, $51 \mathrm{pp}$.

Lee, H.J., B.D. Edwards and M.E. Field, 1981: Geotechnical analysis of a submarine slump, Eureka, California. Proceedings, Offshore Technology Conference, Houston, 53-59.

Mohrig, D., G. Parker and K.X. Whipple, 1995: Hydroplaning of subaqueous debris flows. EOS Transactions of the $A G U, 76, \mathrm{~F} 277$.

Pratson, L.F. and B.J. Coakley, 1996: A model for the headward erosion of submarine canyons induced by downslope eroding sediment flows. Geol. Soc. Am. Bull., 108, 225-234.

Syvitski, J.P., C.R. Alexander, M.E. Field, J.V. Gardner, D.L. Orange and J.W. Yun, 1996: Continental-slope sedimentation: the view from northern California. Oceanography, 9, 163-167.

Terzaghi, K., 1956: Varieties of submarine slope failures. Texas conference on Soil Mechanics and Foundation Engineering, 8th, Proceedings, Texas University Bureau Engineering Research Special Publication 29, 1-41.

Weimer, P. and M.H. Link, 1991: Seismic Facies and Sedimentary Processes of Modern and Ancient Submarine Fans, Frontiers in Sedimentary Geology. Springer-Verlag, New York, 349-363. 